\title{
Article \\ Network-Based Pharmacology Study Reveals Protein Targets for Medical Benefits and Harms of Cannabinoids in Humans
}

\author{
Xingyu Li ${ }^{1,2}{ }^{\mathbb{D}}$, Amit Madhukar Kudke ${ }^{1}$, Felix Joseph Nepveux $\mathrm{V}^{1}$ and Yan $\mathrm{Xu}{ }^{1, *}$ \\ 1 Department of Chemistry, Cleveland State University, Cleveland, OH 44115, USA; \\ lixingyu@ynau.edu.cn (X.L.); a.kudke@vikes.csuohio.edu (A.M.K.); f.j.nepveux@vikes.csuohio.edu (F.J.N.V.) \\ 2 College of Science, Yunnan Agricultural University, Kunming 650201, China \\ * Correspondence: y.xu@csuohio.edu; Tel.: +216-687-3991
}

check for updates

Citation: Li, X.; Madhukar Kudke, A.; Joseph Nepveux V, F; Xu, Y.

Network-Based Pharmacology Study Reveals Protein Targets for Medical Benefits and Harms of Cannabinoids in Humans. Appl. Sci. 2022, 12, 2205. https://doi.org/10.3390/ app12042205

Academic Editors: Tomasz Sawicki, Adam Jurgoński and

Ewa Niedźwiedzka

Received: 26 December 2021

Accepted: 17 February 2022

Published: 20 February 2022

Publisher's Note: MDPI stays neutral with regard to jurisdictional claims in published maps and institutional affiliations.

Copyright: (C) 2022 by the authors. Licensee MDPI, Basel, Switzerland. This article is an open access article distributed under the terms and conditions of the Creative Commons Attribution (CC BY) license (https:// creativecommons.org/licenses/by/ $4.0 /)$.

\begin{abstract}
This network-based pharmacology study intends to uncover the underlying mechanisms of cannabis leading to a therapeutic benefit and the pathogenesis for a wide range of diseases claimed to benefit from or be caused by the use of the cannabis plant. Cannabis contains more than $600 \mathrm{chem}-$ ical components. Among these components, cannabinoids are well-known to have multifarious pharmacological activities. In this work, twelve cannabinoids were selected as active compounds through text mining and drug-like properties screening and used for initial protein-target prediction. The disease-associated biological functions and pathways were enriched through GO and KEGG databases. Various biological networks [i.e., protein-protein interaction, target-pathway, pathwaydisease, and target-(pathway)-target interaction] were constructed, and the functional modules and essential protein targets were elucidated through the topological analyses of the networks. Our study revealed that eighteen proteins (CAT, COMT, CYP17A1, GSTA2, GSTM3, GSTP1, HMOX1, AKT1, CASP9, PLCG1, PRKCA, PRKCB, CYCS, TNF, CNR1, CNR2, CREB1, GRIN2B) are essential targets of eight cannabinoids (CBD, CBDA, $\Delta^{9}-\mathrm{THC}, \mathrm{CBN}, \mathrm{CBC}, \mathrm{CBGA}, \mathrm{CBG}, \Delta^{8}-\mathrm{THC}$ ), which involve in a variety of pathways resulting in beneficial and adverse effects on the human body. The molecular docking simulation confirmed that these eight cannabinoids bind to their corresponding protein targets with high binding affinities. This study generates a verifiable hypothesis of medical benefits and harms of key cannabinoids with a model which consists of multiple components, multiple targets, and multiple pathways, which provides an important foundation for further deployment of preclinical and clinical studies of cannabis.
\end{abstract}

Keywords: Cannabis; cannabinoids; cannabidiol; tetrahydrocannabinol; network-based pharmacology; molecular docking simulation

\section{Introduction}

Cannabis is an annual herbaceous flowering plant in the Cannabaceae family. While there are differences in chemical contents and plant domestication phases (e.g., C. sativa L, C. Lam, and C. ruderalis Janisch), this plant is often considered as a single undivided species, C. sativa or cannabis $[1,2]$.

Chemically, cannabis can be grouped into three types according to the contents of its main cannabinoids, tetrahydrocannabinol (THC) and cannabidiol (CBD): Type I, high THC $(>0.3 \%)$ and low CBD $(<0.5 \%)$; Type II, high THC $(>0.3 \%)$ and high CBD $(>0.5 \%)$; and Type III, low THC (<0.3\%) and high CBD (>0.5\%) [3]. As commodity products, Cannabis can be produced in two major categories: marijuana (Types I and II) and hemp (Type III) [4]. Marijuana is used recreationally or medicinally for its intoxicating properties, but its usage remains illegal in many countries [5]. Hemp is valued for its metabolic compounds, fiber, and seed, which have been used in more than 25,000 products worldwide [6]. Cannabisbased products are documented to have both beneficial and adverse effects. The beneficial effects include treating various diseases, such as cancers, inflammation, pains, epilepsy, 
Parkinson's, Alzheimer's, multiple sclerosis, chronic spasticity, etc., (Table 1(A)); whereas the adverse effects include respiratory and cardiovascular diseases, psychiatric comorbidities, addiction, and impairment of brain development, etc., (Table 1(B)).

Table 1. (A) Clinical conditions/symptoms that may be benefited from the use of cannabis. (B). Adverse effects in humans from the use of cannabis.

\begin{tabular}{|c|c|c|}
\hline \multicolumn{3}{|c|}{ (A) } \\
\hline NO. & Disease & References \\
\hline 1 & Alzheimer's disease & [7] \\
\hline 2 & Amyotrophic lateral sclerosis (ALS) & [8] \\
\hline 3 & Anorexia & {$[7,9]$} \\
\hline 4 & Cancer & {$[8,10]$} \\
\hline 5 & Chronic spasticity & {$[11]$} \\
\hline 7 & Crohn's disease & [8] \\
\hline 8 & $\begin{array}{l}\text { Cutaneous treatment (dermatitis, Sebum's excess \& acne, epidermolysis bullosa, Kaposi } \\
\text { sarcoma, metastatic melanoma) }\end{array}$ & {$[7]$} \\
\hline 9 & Epilepsy & {$[8,9,11,12]$} \\
\hline 10 & Glaucoma & {$[7,9,13]$} \\
\hline 11 & HIV & {$[8,11]$} \\
\hline 12 & Huntington disease & [11] \\
\hline 13 & Infectious Diseases & [7] \\
\hline 14 & Inflammation & {$[8,9,11,13]$} \\
\hline 15 & Inflammatory bowel syndrome (IBS) & [8] \\
\hline 16 & Insomnia & {$[7,11,14]$} \\
\hline 17 & Ischemic stroke & {$[8,15]$} \\
\hline 18 & Malaria & [15] \\
\hline 19 & Multiple sclerosis & {$[7-9,11,13]$} \\
\hline 20 & Nausea and vomiting & {$[7-9,11,14]$} \\
\hline 21 & Anxiety disorders and obsessive-compulsive disorders & [8] \\
\hline 22 & Osteoarthritis & [16] \\
\hline 23 & Pain & {$[7-9,11,13]$} \\
\hline 24 & Parkinson's disease & {$[7,8]$} \\
\hline 25 & Post-traumatic stress disorder (PTSD) & [7] \\
\hline 26 & Tourette's Syndrome & {$[7,11]$} \\
\hline 27 & Uremic pruritus & [14] \\
\hline 28 & Respiratory diseases: airflow obstruction, bronchitis, airway injury & {$[13,17]$} \\
\hline \multicolumn{3}{|c|}{ (B) } \\
\hline NO. & Disease & References \\
\hline 1 & $\begin{array}{l}\text { Impairment of brain development of fetus and adolescence, impaired brain connectivity, } \\
\text { cognitive and motor functions, learning ability, and memory }\end{array}$ & {$[8,9,11,13]$} \\
\hline 2 & Psychiatric comorbidities: depression, anxiety, dysphoria, delusions, bipolar disorder & {$[9,11,13]$} \\
\hline 3 & Schizophrenia: hallucinations, paranoia, and disorganized thinking & {$[8,9,11,17]$} \\
\hline 4 & $\begin{array}{l}\text { Cannabis use disorders and withdrawal symptoms: dizziness, dry mouth, somnolence, } \\
\text { and confusion; restless, irritability, mild agitation, insomnia, nausea, and cramping }\end{array}$ & {$[9,10,14]$} \\
\hline 5 & Cannabinoid hyperemesis syndrome: nausea, vomiting, and dehydration & [18] \\
\hline 6 & Addiction/substance dependence & {$[8,11,13]$} \\
\hline
\end{tabular}

Since the legalization of human consumption of hemp products by the U.S. Agriculture Improvement Act of 2018 (Available at https:/ / www.congress.gov/115/bills/hr2/BILLS115hr2enr.pdf, accessed on 4 October 2021), the hemp industry experienced a seismic shift and hemp-derived products are rushing into the consumer market even before the US-FDA can determine whether they are safe to be used [19], and consumers' interests in medical uses of Cannabis are skyrocketing [20]. However, little clinical research has been conducted with rigorous scientific evidence to prove the health benefits or harms of Cannabis in humans.

Up to date, more than 600 compounds in 18 different chemical classes have been isolated and characterized from Cannabis [21]. Among 120 cannabinoids from cannabis, the 
psychoactive compound $\Delta^{9}$-THC and the non-psychoactive compound CBD have become synonymous with Cannabis and received much attention, which based-production has been used as pharmaceutical grade products in the United States, Europe, and some Caribbean countries (e.g., Epidiole ${ }^{\circledR}$ and Sative ${ }^{\circledR}$ ) [22]. However, the activities of other cannabinoids are not well understood, and even the non-toxic CBD may also have a negative effect $[23,24]$. Besides, cannabinoids can undergo mutual transformation to generate more bioactive forms under certain conditions, such as enzyme catalysis, heat, light, etc., [25] and these cannabinoids and derived cannabinoids may interact with various targets, including but not limited to endocannabinoid receptors, such as CNR1 and CNR2 to exert their individual pharmacologic effects along with any possible entourage effects [26].

Therefore, to increase our understanding of cannabinoid actions and the underlying molecular mechanisms of a wide range of diseases claimed to be benefited from or induced by the use of the plant, a network-based pharmacology study on multiple compounds, multiple targets, and multiple pathways were performed to investigate the effects of Cannabis on human health. The workflow of this study was shown in Figure 1, where a group of 12 cannabinoids was first selected from herbal medicine databases and literature search, and screened by in silico prediction of drug-like properties; then, the protein targets of the cannabinoids were identified using a pharmacophore database for the construction of the protein-protein-interaction (PPI) network to explore the connectivity among the targets; GO biological functions and KEGG pathways were enriched to create the targetpathway (T-P) network, and the pathway-associated diseases were collected to construct the pathway-disease (P-D) network. Following that, the target-target (T-T) network was created based on T-P interactions, where targets sharing the same pathway were connected, and the network nodes were partitioned into various functional modules based on their biological pathways. Each functional module was evaluated based on its contribution scores (CSs) to various diseases, and the essential protein targets within each module were chosen according to their integrated centrality (IC) values. Finally, the modules with high CSs to relevant beneficial or adverse effects of Cannabis and the protein targets with high IC values within each module, as well as the key cannabinoids binding to the protein targets were identified to explore the effects of Cannabis in humans.

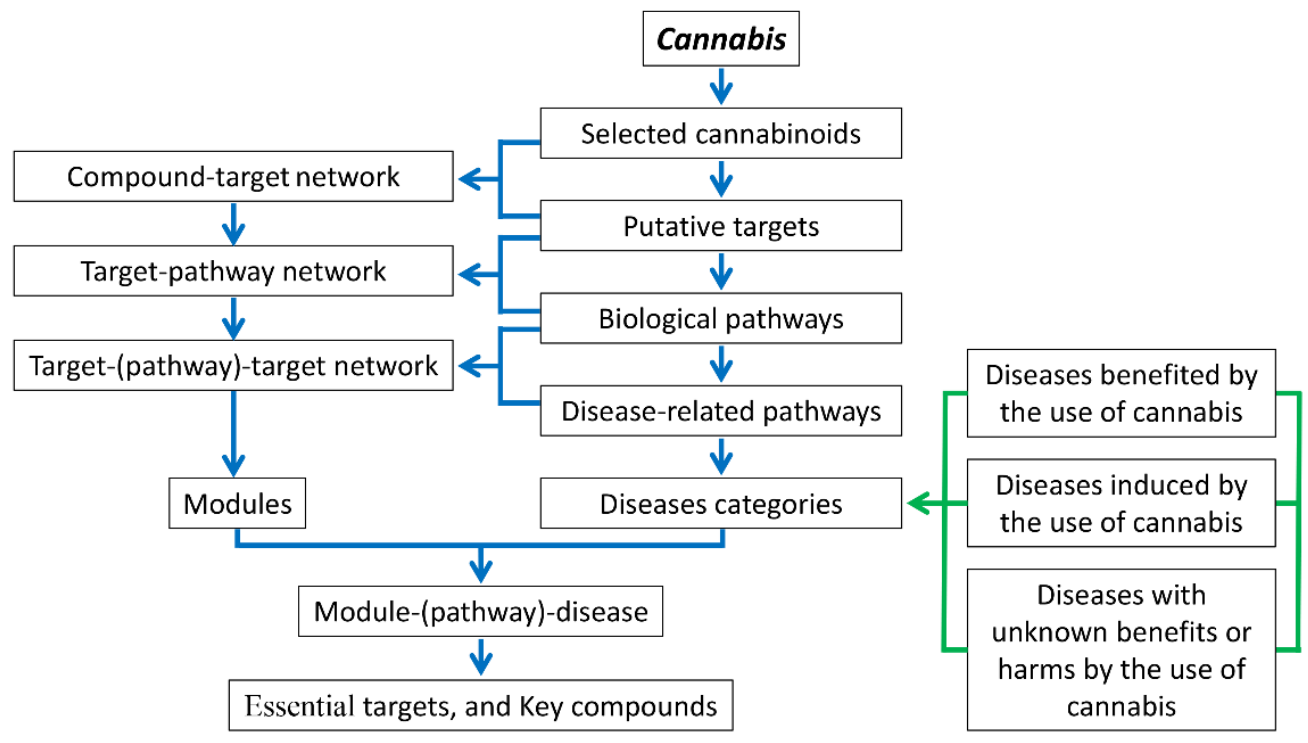

Figure 1. The network pharmacology workflow for this study.

\section{Materials and Methods}

\subsection{Data Acquisition and Processing}

Twelve cannabinoids $\Delta^{9}$-THC, $\Delta^{8}-\mathrm{THC}, 11-\mathrm{OH}-\Delta^{9}-\mathrm{THC}, \Delta^{9}$-THCA, $\Delta^{9}-\mathrm{THCV}, \mathrm{CBN}$, CBD, CBDA, CBDV, CBC, CBG, and CBGA were selected for this study from herbal 
medicine databases including the Traditional Chinese Medicine Systems Pharmacology Database and Analysis Platform (TCMSP v.2.3) (Available at http:/ / tcmspw.com/, accessed on 4 October 2021), the Encyclopedia of Traditional Chinese Medicine (ETCM) (Available at http://www.tcmip.cn/ETCM/, accessed on 4 October 2021), and literature search. The systematic evaluation of drug-likeness, physicochemical, and ADMET properties of the 12 selected cannabinoids was carried out using ADMETlab (Available at http:// admet.scbdd.com, accessed on 4 October 2021) [27]. The two-dimensional (2-D) and three-dimensional (3-D) structures of these cannabinoids were obtained from PubChem (https:/ / pubchem.ncbi.nlm.nih.gov/, accessed on 4 October 2021).

The putative protein targets of the twelve selected cannabinoids were retrieved from PharmMapper, an integrated pharmacophore matching platform with a statistical method for potential target identification (Available at http://www.lilab-ecust.cn/pharmmapper/, accessed on 4 October 2021) with a "fit score" >4 [28]. These targets were used to construct the protein-protein interaction (PPI) network using the online tool STRING v.11.0 (Available at https://string-db.org/, accessed on 4 October 2021). The protein targets with an overall confidence score $>0.4$ [29] were further enriched for relevant diseases and disease-associated pathways using the Kyoto Encyclopedia of Genes and Genomes (KEGG) database (Available at https: / / www.kegg.jp/, accessed on 4 October 2021), as well as biological functions and processes using the Gene Ontology (GO) knowledgebase (Available at http:/ /geneontology.org/, accessed on 4 October 2021) with a $p$-value $<0.01$.

The reported diseases benefited from or induced by the use of Cannabis were searched on ClinicalTrials.gov (https: / / www.clinicaltrials.gov/, accessed on 4 October 2021), GeneCards ${ }^{\circledR}$ (Available at https:/ /www.genecards.org/, accessed on 4 October 2021), Web of Science (Available at https://www.webofknowledge.com/, accessed on 4 October 2021), and Google Scholar (Available at https:/ / scholar.google.com/, accessed on 4 October 2021) using a search string "cannabis" OR "marijuana" OR "hemp" OR "phytocannabinoid" OR "cannabinoid" OR "cannabidiol" OR "tetrahydrocannabinol". Publications included were limited to the English language.

\subsection{Network Construction and Module Identification}

The networks of compound-target (C-T) and protein-protein interaction (PPI) were constructed and visualized using Cytoscape v.3.7.2 (Available at https:/ / cytoscape.org/, accessed on 4 October 2021) [30].

For functional module identification, the two-mode T-P relationships were first transformed into the one-mode target-target (T-T) relationships using Excel2Pajek (Available at http:/ /vlado.fmf.uni-lj.si/pub/networks/pajek/howto/excel2Pajek.htm, accessed on 4 October 2021) [31]. The target-pathway-disease (T-P-D) and T-T network were constructed using Gephi v.0.92 (Available at https:/ / gephi.org/, accessed on 4 October 2021); and the modularity classes were analyzed and identified using the Louvain algorithm with a resolution of 1.0 [32].

\subsection{Contribution Score Calculation}

The contribution score (CS) of a functional module $\left(M_{i}\right)$ to a particular disease $\left(D_{j}\right)$ through a set of common pathways $\left(X_{i j}\right)$ can be calculated as follows:

$$
\begin{aligned}
C_{M_{i} D_{j}}= & \sum_{P_{w} \in X_{i j}} C_{M_{i} P_{w}} C_{P_{w w} D_{j}}=\sum_{P_{w} \in X_{i j}} \frac{1}{\mu_{i w} \times v_{w j}} \\
& (i=1,2,3 \ldots \mathrm{I} ; j=1,2,3 \ldots \mathrm{J} ; w=1,2,3 \ldots \mathrm{W})
\end{aligned}
$$

where $X_{i j}$ refers to a set of pathways that are relevant to $M_{i}$ and $D_{j}$ simultaneously; $C_{M_{i} P_{w}}=\frac{1}{\mu_{i w}}$ refers to the contribution of $\mathrm{M}_{\mathrm{i}}$ to a particular pathway $\left(P_{w}\right)$, where $\mu_{i w}$ is the number of the module(s) related to $P_{w}$, each relevant module contributes $\frac{1}{\mu_{i w}}$ fraction to $P_{w} ; C_{P_{w} D_{j}}=\frac{1}{v_{w j}}$ refers to the contribution of $P_{w}$ to $D_{j}$, where $v_{w j}$ is the number of the pathway(s) related to $D_{j}$, each relevant pathway contributes $\frac{1}{v_{w j}}$ fraction to $D_{j}$; and $C_{M_{i} D_{j}}$ 
refers to the CS of $M_{i}$ to $D_{j}$, which is the sum of the contribution of $M_{i}$ to $D_{j}$ through all the relevant $P_{w}$ in $X_{i j}$. The value of $C_{M_{i} D_{j}}$ ranged from 0 to 1 , the higher the $C S$ value, the greater the contribution of $M_{i}$ to $D_{j}$. The sum of all $C_{M_{i} D_{j}}$ to a particular disease is equal to unity [33].

\subsection{Integrated Centrality Calculation}

The integrated centrality (IC) of a protein target was calculated using the following equation.

$$
\begin{gathered}
\mathrm{IC}_{i}=\frac{1}{4}\left(\frac{\mathrm{DC}_{i}-\mathrm{DC}_{\text {min }}}{\mathrm{DC}_{\max }-\mathrm{DC}_{\text {min }}}+\frac{\mathrm{BC}_{i}-\mathrm{BC}_{\text {min }}}{\mathrm{BC}_{\max }-\mathrm{BC}_{\text {min }}}+\frac{\mathrm{CC}_{i}-\mathrm{CC}_{\text {min }}}{\mathrm{CC}_{\max }-\mathrm{CC}_{\text {min }}}+\frac{\mathrm{EC}_{i}-\mathrm{EC}_{\text {min }}}{\mathrm{EC}_{\text {max }}-\mathrm{EC}_{\text {min }}}\right) \\
(i=1,2,3,4,5,6 \ldots \mathrm{I})
\end{gathered}
$$

where $\mathrm{IC}_{i}$ refers to the integrated centrality of target $i, \mathrm{DC}_{i}, \mathrm{BC}_{i}, \mathrm{CC} i$, and $\mathrm{EC}_{i}$ refer to the degree, betweenness, closeness, and eigenvector centralities of target $i$; $\mathrm{DC}_{\text {min }}, \mathrm{BC}_{\text {min }}$, $\mathrm{CC}_{\text {min, }}$ and $\mathrm{EC}_{\text {min }}$ refer to the minimum degree, betweenness, closeness, and eigenvector centralities of the functional module; and $\mathrm{DC}_{\max }, \mathrm{BC}_{\max }, \mathrm{CC}_{\max }$, and $\mathrm{EC}_{\max }$ refer to the maximum degree, betweenness, closeness, and eigenvector centralities of the functional module. The value of IC ranged from 0 to 1 . The higher the IC value of a target, the more important the target was in its functional module from the topological perspective.

\subsection{Molecular Docking}

To confirm the binding affinity of an essential protein target to a cannabinoid ligand, molecular docking simulation was performed using AutoDock Vina (Available at http: / / vina. scripps.edu/, accessed on 4 October 2021) [34].

The 3-D protein structure was downloaded as a pdb file from the PDB database (Available at https: / / www.rcsb.org/, accessed on 4 October 2021) and uploaded to PyMOL v.2.3 (Available at https:/ / pymol.org/2/, accessed on 4 October 2021) [35] to remove water molecules and other ligands from the structure before it was saved as a pdb file; then polar hydrogens and charges were added to the protein structure using Mgltools (Available at http: / / mgltools.scripps.edu/, accessed on 4 October 2021) [36] and saved as a pdbqt file. The protein grid box was set to cover up the entire protein molecule with a spacing 1 angstrom $(\AA)$ in Mgltool and the grid box coordinates were saved as a text file.

The 3-D cannabinoid structure was downloaded as an sdf file from PubChem (Available at https: / / pubchem.ncbi.nlm.nih.gov /, accessed on 4 October 2021) and converted to a pdb file using Openbabel (Available at http:/ / openbabel.org/wiki/Main_Page, accessed on 4 October 2021) [37]; Then, charges were added and the torsion tree was constructed using Mgltools before it was saved as a pdbqt file.

The blind docking [38] with the AutoDock vina was performed where the protein structure in the pdbqt format was set as the receptor, the cannabinoid structure in the pdbqt format was set as the ligand, and the grid box coordinates were copied from the txt file of the protein grid box. Once the docking was performed, the ligand configurations in the protein structure were generated and saved as a pdbqt file, and the corresponding binding free energy changes $(\Delta G)$ of these configurations were calculated and saved as a log.txt file. The visualization of the docking structures was achieved in PyMOL by uploading both protein structure and ligand configurations in the pdbqt format. The images of molecular docking were exported from PyMOL as png files.

\section{Results and Discussion}

\subsection{Key Cannabinoids}

There are increasing pieces of evidence that the medicinal properties of Cannabis mainly come from cannabinoids [39]. In living and raw Cannabis plants, both cannabigerolic acid (CBGA) and cannabigevarolic acid (CBGVA) are found to be the primary metabolite precursors that can be converted into smaller and more stable cannabinoid acids and 
cannabinoids by enzyme reactions, decarboxylation by heating or smoking, and oxidation by light and air exposures [25,40].

As shown in Figure 2, through enzyme reactions, CBGA turns into tetrahydrocannabinolic acid (THCA), cannabidiolic acid (CBDA), and cannabichromenic acid (CBCA), whereas CBGVA breaks down into cannabichromevarinic acid (CBCVA), cannabidivarinic acid (CBDVA), and tetrahydrocannabivarinic acid (THCVA); by decarboxylation, CBGA becomes cannabigerol (CBG), THCA becomes $\Delta^{9}$-tetrahydrocannabinol $\left(\Delta^{9}-\mathrm{THC}\right), \mathrm{CBDA}$ becomes cannabidiol (CBD), CBCA becomes cannabichromene (CBC), CBGVA becomes cannabigerivarin (CBGV), CBCVA becomes cannabichromevarin (CBCV), CBDVA becomes cannabidivarin (CBDV), and THCVA becomes $\Delta^{9}$-tetrahydrocannabinolic acid $\left(\Delta^{9}\right.$-THCA). Furthermore, $\Delta^{9}$-THC can be converted to cannabinol (CBN) by oxidation and $\Delta^{8}$-tetrahydrocannabinol $\left(\Delta^{8}\right.$-THC) by isomerization, as well as 11 -Hydroxy- $\Delta^{9}$-tetrahydrocannabinol (11-OH- $\left.\Delta^{9}-\mathrm{THC}\right)$ by metabolization. The acidic and neutral forms of phytocannabinoids can undergo further transformation to generate over one hundred different cannabinoids.

Among the cannabinoids discovered, the psychoactive $\Delta^{9}$-THC and the non-psychoactive CBD are the two most abundant cannabinoids, and all other cannabinoids are in trace amounts. The health effects of twelve key cannabinoids including $\Delta^{9}-\mathrm{THC}, \Delta^{8}$-THC, 11-OH- $\Delta^{9}-\mathrm{THC}, \Delta^{9}$-THCA, $\Delta^{9}$-THCV, CBN, CBD, CBDA, CBDV, CBC, CBG, and CBGA have been investigated, the therapeutic benefits of these cannabinoids range from analgesics, anorectic, anxiolytic, appetite stimulant, anti-bacterial, anticonvulsant, anti-diabetic, antiemetic, antiepileptic, anti-fungal, anti-inflammatory, anti-insomnia, anti-ischemic, anti-proliferative, antipsoriatic, antipsychotic, and antispasmodic to bone-stimulant, immunosuppressive, intestinal antiprokinetic, and neuroprotective, etc. [39]. Hence, these cannabinoids were adopted as the chemical markers of the Cannabis potency test (expect 11-OH- $\Delta^{9}$-THC) (Medical Marijuana SCF Technical Guide, Version 5.0, Available at https:/ / www.michigan.gov/documents/lara/FINAL.TESTING.GUIDE_634575_7.pdf, accessed on 4 October 2021).

\subsection{Drug-Like Properties of the Selected Cannabinoids}

Table S1 presented the drug-like properties of the twelve selected cannabinoids obtained by in silico prediction [27]. As shown in Table S1, the selected cannabinoids possess most of the preferable drug-like properties for candidates in drug development; for example, the drug-likeness (DL), blood-brain ratio (BBB), and oral bioavailability (F-20) of these cannabinoids were ranged $0.50-0.87(\geq 0.180), 0.196-0.931(\geq 0.100)$, and $20.6-51.5 \%$ $(\geq 20.0 \%)$, respectively.

\subsection{C-T Network Construction and Analysis}

A total of 234 proteins were retrieved as the putative targets of the twelve selected cannabinoids from PharmMapper (Table S2), and the C-T network was constructed which consisted of 247 nodes and 688 edges with a median degree centrality (DC) of 17 (Figure 3). The CBD had the highest $\mathrm{DC}$ and connecting to 126 protein targets, the second one was CBDA with a DC of 115 , and the third one was $\Delta^{9}$-THC with a DC of 82 , followed by CBN (73), CBC (55), CBGA (44), $\Delta^{8}$-THC (42), CBG (40), $\Delta^{9}$-THCA (37), CBDV (27), 11-OH$\Delta^{9}$-THC (25), and $\Delta^{9}$-THCV (22).

\subsection{PPI Network Construction and Analysis}

The 234 putative protein targets were uploaded to the STRING database for network analysis and the 223 protein targets with overall confidence scores $>0.4$ (Szklarczyk et al., 2019) were used to construct the PPI network which consisted of 223 nodes and 2308 edges with a median DC of 26 (Figure 4). The protein targets with the higher values of DC were INS (105), ALB (104), AKT1 (97), TNF (76), PTGS2 (72), EGFR (72), CXCL8 (64), CAT (64), BDNF (59), and ESR1 (58), respectively, indicating their important roles in the PPI network. 
<smiles>C=C(O)C1CCC(C)=CC1c1c(O)cc(CCCCC)cc1O</smiles>

(4) CBD<smiles>C=C1CCC(C)=CC1c1c(O)cc(CCCCC)c(C(=O)O)c1OCI</smiles>

(3) CBDA<smiles>CCCCCc1cc(O)c2c(c1)OC(C)(C)c1ccc(C)cc1-2</smiles>

CBNA<smiles>CCCCCc1cc(O)c2c(c1)OC(C)(C)c1ccc(C)cc1-2</smiles>

(9) $\mathrm{CBN}$<smiles>CCCCCc1cc(O)c(C/C=C(\C)CCC=C(C)C)c(O)c1</smiles>

(2) CBG<smiles>CCCCCc1cc(O)c2c(c1)O[C@](C)(CCC=C(C)C)C=C2</smiles><smiles>CC(C)C</smiles><smiles>CCCCCc1cc(O)c(C/C=C(/C)CCC)c(O)c1C(=O)O</smiles><smiles>CCCCCc1cc2c(c(O)c1C(=O)O)C=C[C@](C)(CCC=C(C)C)O2</smiles><smiles>CCC</smiles>

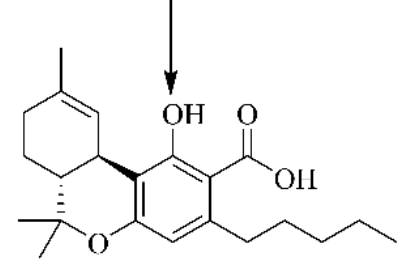

(6) $\triangle^{9}$-THCA

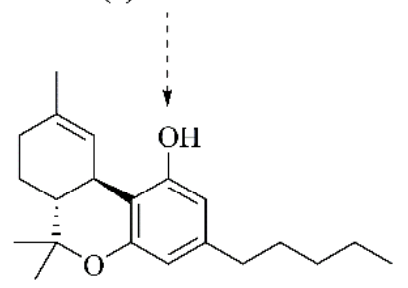

(7) $\Delta^{9}$-THC

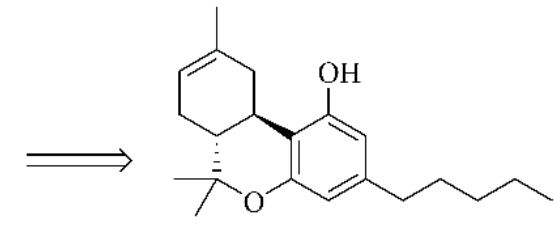

(8) $\triangle^{8}$-THC

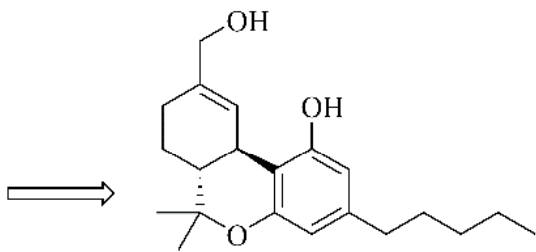

(10) 11-OH- $\Delta^{9}-\mathrm{THC}$<smiles>C=C(O)[C@H]1CCC(C)=C[C@H]1c1c(O)cc(CCC)cc1O</smiles>

(12) CBDV<smiles>C=C(O)[C@H]1C=C(C)CC[C@H]1c1c(O)cc(CCC)c(C(=O)O)c1O</smiles>

CBDVA

$\longrightarrow$ Acid Synthase

-.. Decarboxylation (by heating or smoking)

- Oxidation (by light and air exposures)

$\Longrightarrow$ Metabolized Through Consumption

$\Longrightarrow$ Isomerization<smiles>CCCc1cc(O)c(C/C=C(\C)CCC=C(C)C)c(O)c1</smiles>

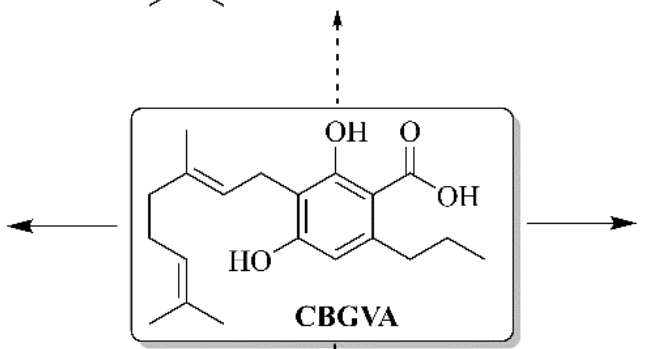<smiles>CCCc1cc(O)c2c(c1)O[C@](C)(CCC=C(C)C)C=C2</smiles><smiles>CCCc1cc2c(c(O)c1C(=O)O)C=C[C@](C)(CCC=C(C)C)O2</smiles>

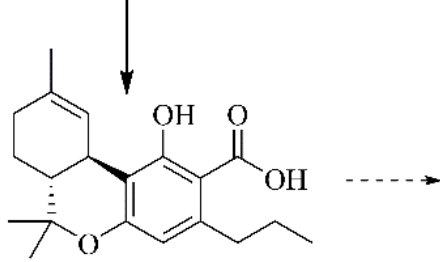

$\triangle^{9}$-THCVA

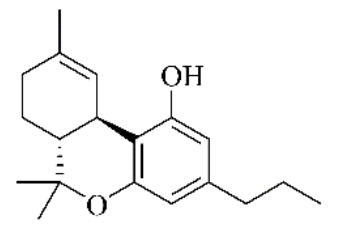

(11) $\triangle^{9}$-THCV

Figure 2. The chemical structures of twelve key cannabinoids and their biosynthesis pathways $[25,40]$. 


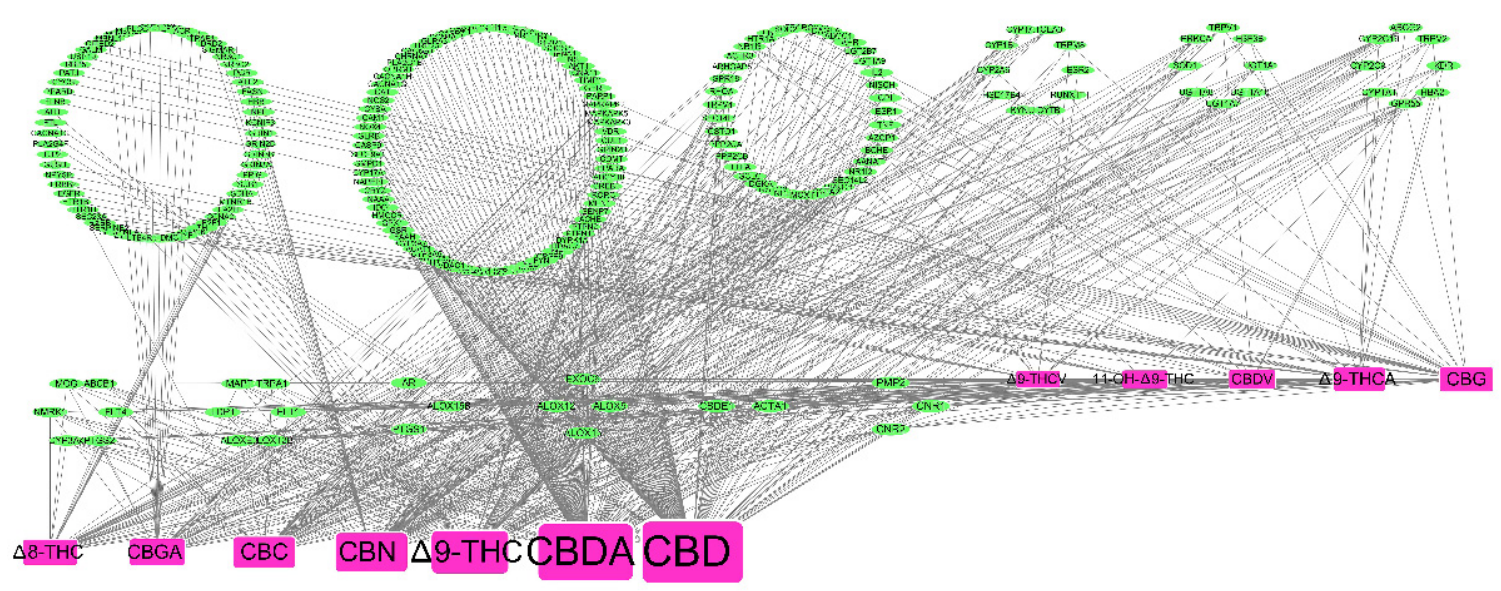

Figure 3. In the compounds-targets interaction network, the green ovals represent the targets, the red rectangles represent the cannabinoids, and the node size is proportional to its degree centrality.

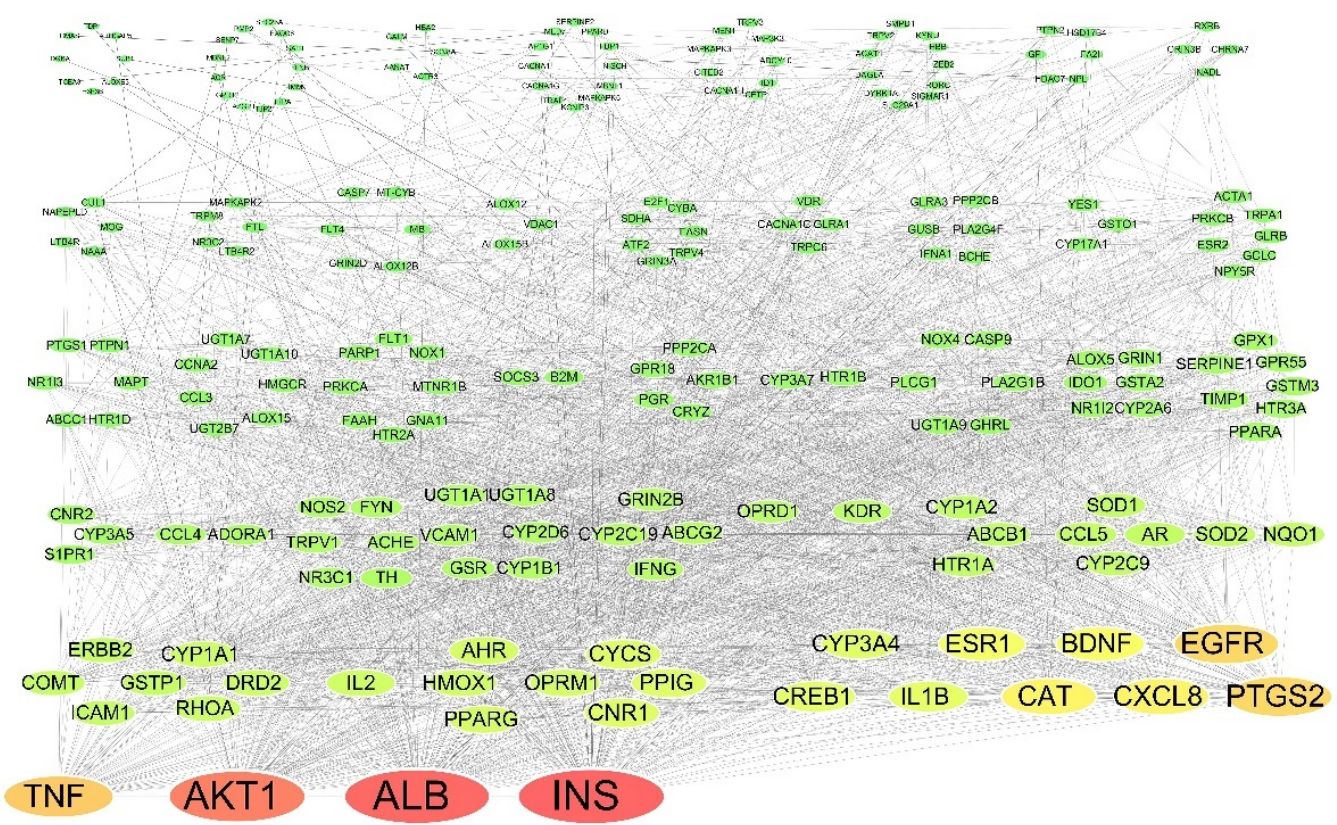

Figure 4. Protein-protein interaction network, the green oval represents the target, the size of the node is proportional to its degree centrality, and the color of the node gradually changes from red, yellow, and then green as the degree centrality decreases. Table S1. The putative targets of the twelve selected cannabinoids were predicted using PharmMapper.

\subsection{GO Biological Function and KEGG Pathway Enrichment Analysis}

Enrichment analysis of GO biological functions and KEGG pathways on the 223 protein targets resulted in $140 \mathrm{GO}$ terms (Table S3) whose top 10 were shown in Figure 5A, and 101 KEGG pathways (Table S4) whose top 10 were shown in Figure 5B. All 101 KEGG pathways were mapped by five pathway categories that were cellular processes, environmental information processing, human diseases, metabolism, and organismal systems (Figure 5C). There were 65 KEGG disease entries found to be associated with some of these pathways (Table S5) which were classified into 10 disease categories (Figure 5D), including one cardiovascular disease, one urinary system disease, two nervous system diseases, one congenital malformation, thirteen cancers, six endocrine and metabolic diseases, six immune system diseases, six mental and behavioral disorders, six neurodegenerative diseases, and 23 infectious diseases. Among the 65 disease entries, 60 diseases had pathways associated with human diseases, three diseases had pathways related to environmental 
information processing, and two diseases had pathways related to organismal systems and metabolism, respectively.

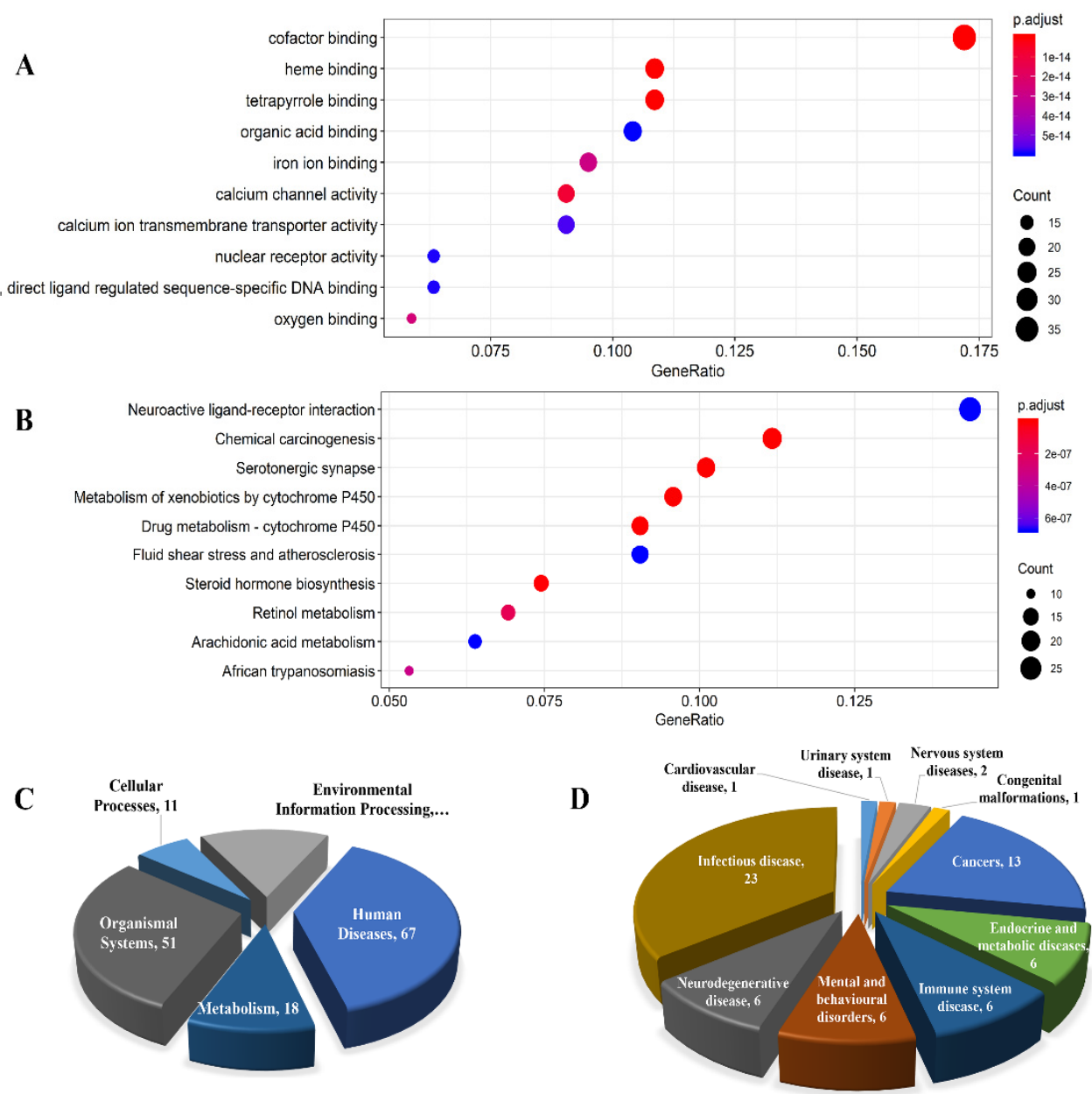

Figure 5. (A) The top 10 items of GO biological function enrichment; (B) the top 10 items of KEGG pathway enrichment; (C) the categories of the pathways enriched; and (D) the disease categories of KEGG enrichment.

According to the documented beneficial and adverse effects of Cannabis use in humans (Table 1), the 65 disease entries were divided into three groups (Table S5): Group I (beneficial) consisted of 32 diseases that were reported to be benefited from the use of Cannabis [41,42]; Group II (adverse) included six diseases that were reported to be induced by the use of Cannabis [43]; and Group III (unknown) had 27 diseases that had not been reported to be affected by the use of Cannabis.

\subsection{Network Construction and Module Identification}

The T-P-D network of the Group I and Group II diseases was constructed using Gephi, which consisted of 196 nodes (i.e., 122 targets, 36 pathways, and 38 diseases) and 392 edges (Figure 6A). As shown in Figure 6A, a target in the network was connected to either one or multiple pathways and a pathway was connected to either one or multiple diseases. To extract the relationship among the targets, the T-T network was constructed through the corresponding relationships between targets and pathways, where the edges of the network represent the common pathways between every two targets. A functional module of targets was identified through a set of shared pathways using Gephi with the Louvain algorithm (Figure 6B). 
A

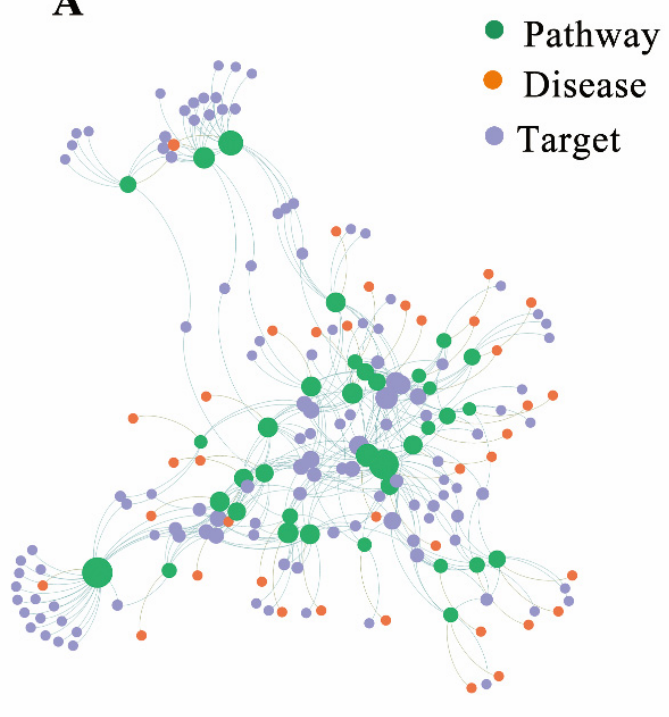

B

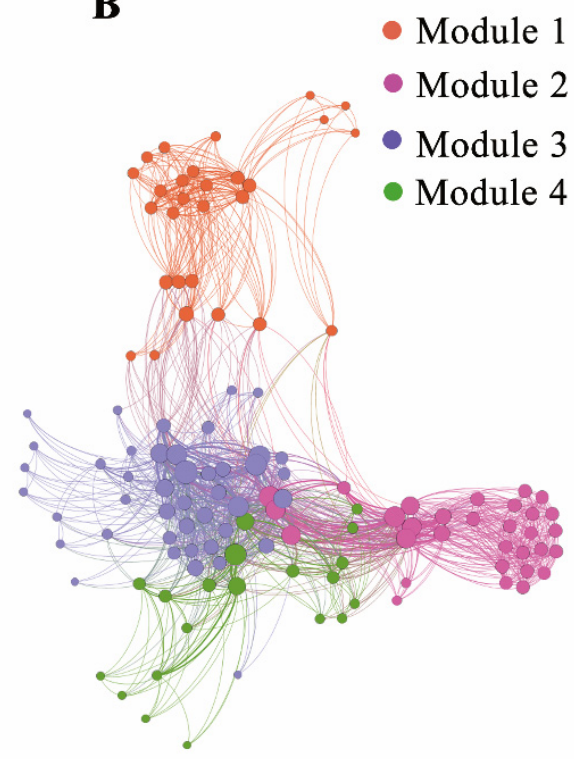

Figure 6. (A) The target-pathway-disease interaction network and (B) The target-(Pathway)-Target interaction network with modularity partition by Gephi with Louvain algorithm, where the nodes were targets and the edges were the shared pathways of these targets.

As shown inFigure 6B, four functional modules (Modules 1-4) were identified, where Module 1 consisted of 28 targets ( $22.95 \%$ of total targets) that were connected by eight pathways, such as amyotrophic lateral sclerosis (hsa05014), hepatocellular carcinoma (hsa05225), prostate cancer (hsa05215), and so on. Module 2 consisted of 43 targets (35.25\%) that were connected by 27 pathways, such as Huntington disease (hsa05016), Parkinson's disease (hsa05012), Alzheimer's disease (hsa05010), and so on. Module 3 consisted of 20 targets $(16.39 \%)$ that were connected by 17 pathways, such as human T-cell leukemia virus 1 infection (hsa05166), type II diabetes mellitus (hsa04930), inflammatory bowel disease (hsa05321), and so on. Module 4 consisted of 31 targets (25.41\%) that were connected by 17 pathways, such as alcohol dependence (hsa05034), nicotine addiction (hsa05033), cocaine addiction (hsa05030), and so on.

\subsection{Contribution Scores}

The contribution of each functional module of targets to a particular disease through a set of common pathways can be evaluated using the CS of each module. The CSs of the four functional modules to 38 diseases were calculated using Equation (1) (see Section 2.3) and tabulated in Figure 7. The sum of the CSs from each of the four modules for a particular disease was 1 or unity. The larger the CS value of a module, the greater the contribution of the module to a disease became.

As shown in Figure 7, the health benefits of 11 out of 32 Group I diseases (Table S5) were attributed to a single functional module $(\mathrm{CS}=1.00)$ [i.e., primary congenital glaucoma (h01203) was associated with the targets in Module 1; breast cancer (H00031), endometrial cancer (H00026), gastric cancer (H00018), glioma (H00042), non-small cell lung cancer (H00014), pancreatic cancer (H00019) were connected with the targets in Module 2; malaria (H00361), inflammatory bowel disease (H01227), and ulcerative colitis (H01466) were related to the targets in Module 3; and autosomal dominant nocturnal frontal lobe epilepsy (H00807) was accredited to the targets in Module 4]; whereas the health benefits of the other 21 Group I diseases were attributed to the targets in two or three or even four functional modules. Similarly, the medical harms of six Group II diseases (Figure 7, Table S5) came from the targets of one functional module [i.e., Module 4 for alcohol dependence (H01611), cocaine addiction (H0000A), and nicotine addiction (H0000D)] or targets of two functional modules [i.e., Module 2 and Module 4 for amphetamine addiction (H0000B) and morphine 
addiction (H0000C)] or targets of three functional modules [i.e., Module 1, Module 2 and Module 4 for Schizophrenia (H01649)]. Since Cannabis addiction has not been documented in the KEGG database and the protein targets of Module 4 are prone to cannabinoid ligands and associated with various substance dependence including alcohol, cocaine, nicotine, amphetamine, and morphine addiction, it is reasonable for one to speculate that Cannabis addiction shares the same pathways and protein targets of Module 4. This may explain why the use of Cannabis could cross-sensitize the addictive effects of nicotine and morphine $[44,45]$.

\begin{tabular}{|c|c|c|c|c|c|c|}
\hline Module 1 & Module 2 & Module 3 & Module 4 & Disease ID & Disease & Group \\
\hline 1.00 & 0.00 & 0.00 & 0.00 & H01203 & Primary congenital glaucoma & \multirow{32}{*}{ Group I } \\
\hline 0.00 & 1.00 & 0.00 & 0.00 & $\mathrm{H} 00031$ & Breast cancer & \\
\hline 0.00 & 1.00 & 0.00 & 0.00 & H00026 & Endometrial cancer & \\
\hline 0.00 & 1.00 & 0.00 & 0.00 & $\mathrm{H} 00018$ & Gastric cancer & \\
\hline 0.00 & 1.00 & 0.00 & 0.00 & $\mathrm{H} 00042$ & Glioma & \\
\hline 0.00 & 1.00 & 0.00 & 0.00 & H00014 & Non-small cell lung cancer & \\
\hline 0.00 & 1.00 & 0.00 & 0.00 & H00019 & Pancreatic cancer & \\
\hline 0.50 & 0.50 & 0.00 & 0.00 & $\mathrm{H} 00048$ & Hepatocellular carcinoma & \\
\hline 0.00 & 0.50 & 0.50 & 0.00 & $\mathrm{H} 00022$ & Bladder cancer & \\
\hline 0.00 & 0.50 & 0.50 & 0.00 & H00020 & Colorectal cancer & \\
\hline 0.00 & 0.50 & 0.50 & 0.00 & $\mathrm{H} 00013$ & Small cell lung cancer & \\
\hline 0.00 & 0.33 & 0.33 & 0.33 & H00009 & Adult T-cell leukemia & \\
\hline 0.00 & 0.33 & 0.33 & 0.33 & H00041 & Kaposi sarcoma & \\
\hline 0.33 & 0.33 & 0.00 & 0.33 & $\mathrm{H} 00024$ & Prostate cancer & \\
\hline 0.00 & 0.50 & 0.50 & 0.00 & $\mathrm{H} 00406$ & Acquired immunodeficiency syndrome & \\
\hline 0.00 & 0.50 & 0.50 & 0.00 & H01563 & HIV infection & \\
\hline 0.00 & 0.00 & 1.00 & 0.00 & H00361 & Malaria & \\
\hline 0.00 & 0.00 & 1.00 & 0.00 & $\mathrm{H} 01227$ & Inflammatory bowel disease & \\
\hline 0.00 & 0.00 & 1.00 & 0.00 & H01466 & Ulcerative colitis & \\
\hline 0.00 & 0.50 & 0.50 & 0.00 & $\mathrm{H} 01672$ & Juvenile idiopathic arthritis & \\
\hline 0.00 & 0.50 & 0.50 & 0.00 & $\mathrm{H} 00630$ & Rheumatoid arthritis & \\
\hline 0.33 & 0.33 & 0.00 & 0.33 & H02049 & Bilateral macronodular adrenal hyperplasia & \\
\hline 0.00 & 0.50 & 0.50 & 0.00 & H00408 & Type 1 diabetes mellitus & \\
\hline 0.00 & 0.50 & 0.50 & 0.00 & H00409 & Type 2 diabetes mellitus & \\
\hline 0.00 & 0.00 & 0.00 & 1.00 & H00807 & Autosomal dominant nocturnal frontal lobe epilepsy & \\
\hline 0.00 & 0.33 & 0.33 & 0.33 & $\mathrm{H} 00808$ & Idiopathic generalized epilepsies & \\
\hline 0.00 & 0.33 & 0.33 & 0.33 & $\mathrm{H} 00056$ & Alzheimer disease & \\
\hline 0.00 & 0.33 & 0.33 & 0.33 & H00059 & Huntington disease & \\
\hline 0.00 & 0.33 & 0.33 & 0.33 & H00057 & Parkinson disease & \\
\hline 0.25 & 0.25 & 0.25 & 0.25 & $\mathrm{H} 00058$ & Amyotrophic lateral sclerosis & \\
\hline 0.25 & 0.25 & 0.25 & 0.25 & $\mathrm{H} 00970$ & Juvenile primary lateral sclerosis & \\
\hline 0.00 & 0.33 & 0.33 & 0.33 & H01657 & Nephrotic syndrome & \\
\hline 0.00 & 0.00 & 0.00 & 1.00 & H01611 & Alcohol dependence & \multirow{6}{*}{ Group II } \\
\hline 0.00 & 0.00 & 0.00 & 1.00 & $\mathrm{H} 0000 \mathrm{~A}$ & Cocaine addiction & \\
\hline 0.00 & 0.00 & 0.00 & 1.00 & H0000D & Nicotine addiction & \\
\hline 0.00 & 0.50 & 0.00 & 0.50 & H0000B & Amphetamine addiction & \\
\hline 0.00 & 0.50 & 0.00 & 0.50 & $\mathrm{H} 0000 \mathrm{C}$ & Morphine addiction & \\
\hline 0.33 & 0.33 & 0.00 & 0.33 & H01649 & Schizophrenia & \\
\hline
\end{tabular}

Figure 7. The contribution scores (CS) of each module to various diseases.

\subsection{Integrated Centrality and Essential Protein Targets}

Biological networks are heterogeneous by nature, where the connecting nodes play very different roles in structure and function, and the importance of nodes can be described by network centrality [26].However, a single centrality measure (such as degree centrality, betweenness centrality, closeness centrality, and eigenvector centrality, etc.) would not be sufficient to predict the essential nodes in biological networks; therefore, integrating various centrality measures is a preferred way to predict the essential nodes in the biological systems [46]. In this work, IC values were determined using Equation (2) (see Section 2.4) (Table S6) and the IC values $>0.5$ were used to predict the essential protein targets in each functional module [33]. Table 2 listed eighteen essential protein targets of cannabinoids, including 16 targets selected by IC values and two targets (i.e., CNR1 and CNR2) supported by text mining of biomedical literature $[39,47,48]$, and 8 cannabinoid ligands that bind to these targets. 
Table 2. The essential protein targets and their corresponding cannabinoid ligands.

\begin{tabular}{|c|c|c|c|c|c|c|}
\hline No. & Target & Description & Uniprot & IC & Module & Cannabinoid Ligands \\
\hline 1 & CAT & Catalase & P04040 & 0.63 & 1 & CBD, CBDA \\
\hline 2 & COMT & Catechol-O-methyltransferase & P21964 & 0.57 & 1 & $\Delta^{9}-\mathrm{THC}, \mathrm{CBN}$ \\
\hline 3 & CYP17A1 & $\begin{array}{l}\text { Cytochrome P450 family } 17 \text { subfamily A } \\
\text { member } 1\end{array}$ & P05093 & 0.56 & 1 & $\mathrm{CBD}, \mathrm{CBDA}$ \\
\hline 4 & GSTA2 & Glutathione S-transferase alpha 2 & P09210 & 0.51 & 1 & $\Delta^{9}-\mathrm{THC}, \mathrm{CBC}, \mathrm{CBN}$ \\
\hline 5 & GSTM3 & Glutathione S-transferase mu 3 & P21266 & 0.64 & 1 & $\Delta^{9}-\mathrm{THC}, \mathrm{CBC}, \mathrm{CBN}$ \\
\hline 6 & GSTP1 & Glutathione S-transferase pi 1 & P09211 & 0.72 & 1 & $\Delta^{9}-\mathrm{THC}, \mathrm{CBC}, \mathrm{CBN}$ \\
\hline 7 & HMOX1 & Heme oxygenase 1 & P09601 & 0.52 & 1 & $\Delta^{9}-\mathrm{THC}, \mathrm{CBC}, \mathrm{CBN}$ \\
\hline 8 & AKT1 & AKT serine/threonine kinase 1 & P31749 & 0.81 & 2 & $\mathrm{CBD}, \mathrm{CBDA}$ \\
\hline 9 & CASP9 & Caspase 9 & P55211 & 0.67 & 2 & $\mathrm{CBD}, \mathrm{CBDA}$ \\
\hline 10 & PLCG1 & Phospholipase C gamma 1 & P19174 & 0.51 & 2 & CBGA \\
\hline 11 & PRKCA & Protein kinase $\mathrm{C}$ alpha & P17252 & 0.65 & 2 & $\begin{array}{c}\Delta^{9}-\mathrm{THC}, \mathrm{CBC}, \mathrm{CBD}, \mathrm{CBDA}, \\
\text { CBN }\end{array}$ \\
\hline 12 & PRKCB & Protein kinase $\mathrm{C}$ beta & P05771 & 0.56 & 2 & $\Delta^{9}-\mathrm{THC}, \mathrm{CBC}, \mathrm{CBN}$ \\
\hline 13 & CYCS & Cytochrome c, somatic & P99999 & 0.59 & 3 & CBG \\
\hline 14 & TNF & Tumor necrosis factor & P01375 & 0.55 & 3 & $\Delta^{8}-\mathrm{THC}, \mathrm{CBD}, \mathrm{CBDA}$ \\
\hline 15 & CNR1 & Cannabinoid receptor 1 & P21554 & 0.20 & 4 & $\begin{array}{c}\Delta^{8}-\mathrm{THC}, \Delta^{9}-\mathrm{THC}, \mathrm{CBC}, \mathrm{CBD}, \\
\text { CBDA, CBG, CBGA, CBN }\end{array}$ \\
\hline 16 & CNR2 & Cannabinoid receptor 2 & P34972 & 0.20 & 4 & $\begin{array}{c}\Delta^{8}-\mathrm{THC}, \Delta^{9}-\mathrm{THC}, \mathrm{CBC}, \mathrm{CBD}, \\
\text { CBDA, CBG, CBGA, CBN }\end{array}$ \\
\hline 17 & CREB1 & $\begin{array}{c}\text { cAMP-responsive element binding } \\
\text { protein } 1\end{array}$ & P16220 & 0.63 & 4 & $\Delta^{9}-\mathrm{THC}, \mathrm{CBN}$ \\
\hline 18 & GRIN2B & $\begin{array}{c}\text { Glutamate ionotropic receptor NMDA } \\
\text { type subunit } 2 \mathrm{~B}\end{array}$ & Q13224 & 0.68 & 4 & $\Delta^{9}-\mathrm{THC}, \Delta^{8}-\mathrm{THC}$ \\
\hline
\end{tabular}

These 18 essential protein targets of cannabinoids include seven from Module 1 (i.e., CAT, COMT, CYP17A1, GSTA2, GSTM3, GSTP1, and HMOX1), five from Module 2 (i.e., AKT1, CASP9, PLCG1, PRKCA, and PRKCB), two from Module 3 (i.e., CYCS and TNF), and four from Module 4 (i.e., CNR1, CNR2, CREB1, and CRIN2B). The health benefits or medical harms of cannabinoids on humans may come from the combined modulation which perturbs the functional modules of various diseases upon the binding of multiple cannabinoid ligands to the multiple essential protein targets to achieve restoration of homeostasis or induction of diseases due to the agonist or antagonist activities of the cannabinoids [49].

Many of these essential protein targets have been reported to interact with cannabinoids and are associated with Groups I and II diseases. For example, Both CNR1 and CNR2 are members of the GPCR family and are largely involved in various activities and disorders of the central nervous system, including learning and memory, appetite, anxiety, depression, stroke, schizophrenia, multiple sclerosis, neurodegenerative diseases, epilepsy, pain, and addiction [50-52]. Several variations of CNR1 have been reported to be associated with Cannabis dependence [53-55]. THC suppresses soluble macrophage tumoricidal activity and partially inhibits TNF signals [56], CBD prevents ischemic injury by partially inhibiting TNF [57], and CBD and its analogs had an inhibitory effect on TNF production by lipopolysaccharide-stimulated macrophages [58]. THCA has been known to suppress the expression of TNF in vitro, suggesting a mechanism for immune modulation [59]. AKT1, the serine-threonine protein kinase commonly referred to as protein kinase $B(\mathrm{PKB})$, is a critical mediator of growth factor-induced neuronal survival and critical for transmitting growth-promoting signals. Gene polymorphisms in AKT1 have been shown to play a mediating role between Cannabis exposure and the development of psychosis, indicating the AKT1 pathway is a possible target for the prevention and treatment of Cannabis-related psychosis [60]. GRIN2B encoding two essential $N$-methyl-d-aspartate (NMDA) subunits have been shown to have a combined effect on the pathogenesis of Schizophrenia and are involved in regulating cortical excitability and plasticity [61]. Moreover, GRIN2B gene products play a fundamental role in many brain functions. A growing number of studies 
have shown that GRIN2B is significantly associated with depression and disruptive behavior, mood disorders, and bipolar disorder [61]. Besides, various studies have shown that GRIN2B is associated with cocaine and alcohol abusers, which may be related to the shared pathway of addiction [62]. CASP9 belongs to a family of caspases that play essential roles in programmed cell death. Cannabinoids like CBD and $\Delta^{9}$-THC have been proved to play role in the modulation of tumor proliferation, cell cycle, and apoptosis in various cancer types through activating CASP9 leading to apoptosis [63,64]. CREB1, which encodes cyclic adenosine monophosphate reactive element-binding protein 1, plays a core role in intracellular signal transduction and plays a significant character in a variety of cellular functions. It has been implicated in anxiety, depression [65], mood disorders [66], and drug addiction [67]. PRKCA and PRKCB have been mentioned in substance dependence [68,69].

\subsection{Molecule Docking}

The bindings of essential protein targets to the eight key cannabinoid ligands were further confirmed by molecular docking simulation using Autodock Vina. The binding affinity of a ligand-target complex was evaluated by the binding energy $(\Delta G$, binding free energy change), where a more negative binding energy value indicates a stronger binding affinity or a greater binding constant for the formation of the ligand-target complex. In this work, the binding energies calculated were based on the complex conformation with the lowest docking energy. Table ?? showed the binding energies of the eight key cannabinoid ligands to the 18 essential protein targets, which had values ranging from $-10.5 \mathrm{kcal} / \mathrm{mol}$ to $-4.7 \mathrm{kcal} / \mathrm{mol}$. The binding energy of $\leq-5.0 \mathrm{kcal} / \mathrm{mol}$ indicates the strong binding between a ligand and its target [70-72]. The strongest binding was observed between CBDA and TNF with a binding energy of $-10.5 \mathrm{kcal} / \mathrm{mol}$. Figure 8 illustrated the binding of CBDA to TNF at the binding pocket where hydrophobic interactions were observed between amino acid residues at GLY-121, LEU-120, LEU-57, SER-60, TYR-119, TYR-151, and TYR-59; and H-bonds were formed at GLY-121, LEU-120, and SER-60 with distances of $3.2 \AA, 3.4 \AA$ and $2.5 \AA$, respectively. Since the stronger the binding affinity of a ligand to its protein target, the higher the potency of the ligand, the binding affinity data can guide us to select the proper ligand-targets pairs from each functional module for experimental validation of the efficacy of cannabinoid for the aimed illnesses and therapeutic outcomes.

\begin{tabular}{|c|c|c|c|c|c|c|c|c|}
\hline $\begin{array}{ll}\text { Target (PDB-ID) } & \text { Ligands } \\
\end{array}$ & $\Delta 8-\mathrm{THC}$ & $\triangle 9-\mathrm{THC}$ & СВС & CBD & CBDA & CBG & CBGA & CBN \\
\hline AKT1 $(6 S 9 W)$ & 1 & 1 & 1 & -8.6 & -8.8 & 1 & 1 & 1 \\
\hline CASP9 (4RHW) & / & / & / & -5.8 & -5.9 & / & / & / \\
\hline CAT (1DGF) & / & / & / & -7.5 & -7.9 & l & / & / \\
\hline COMT (4PYI) & / & -8.0 & l & l & l & l & / & -8.0 \\
\hline CREB1 (5ZKO) & / & -5.8 & / & / & / & / & / & -6.6 \\
\hline CYCS (5TY3) & / & / & / & l & / & -4.7 & / & / \\
\hline CYP17A1 (6WR1) & l & l & / & -7.4 & -7.0 & / & / & / \\
\hline GRIN2B (5EWM) & -7.6 & -8.0 & / & / & / & l & / & / \\
\hline GSTA2 (5LD0) & / & -7.0 & -5.4 & l & I & l & / & -6.5 \\
\hline GSTM3 (3GTU) & / & -7.7 & -6.7 & l & l & l & / & -7.6 \\
\hline GSTP1 (5J41) & I & -8.7 & -7.6 & I & I & I & I & -8.1 \\
\hline HMOX1 (1N45) & l & -8.0 & -7.4 & l & l & l & / & -7.7 \\
\hline PLCG1 (3GQI) & / & / & l & l & l & l & -5.6 & / \\
\hline PRKCA (4RA4) & I & -7.5 & -7.8 & -6.7 & -7.4 & I & / & -8.2 \\
\hline PRKCB (2I0E) & I & -8.1 & -8.1 & l & 1 & l & I & -8.5 \\
\hline TNF (6OOY) & -10.4 & / & / & -6.0 & -10.5 & / & / & / \\
\hline CNR1 (5U09) & -7.9 & -7.6 & -7.0 & -7.3 & -7.1 & -7.9 & -6.9 & -9.4 \\
\hline CNR2 (6KPC) & -8.0 & -8.2 & -7.7 & -9.2 & -7.3 & -6.9 & -7.0 & -8.5 \\
\hline
\end{tabular}

Symbol, /, means that there is no predicted binding between a cannabinoid ligand and a protein target. 

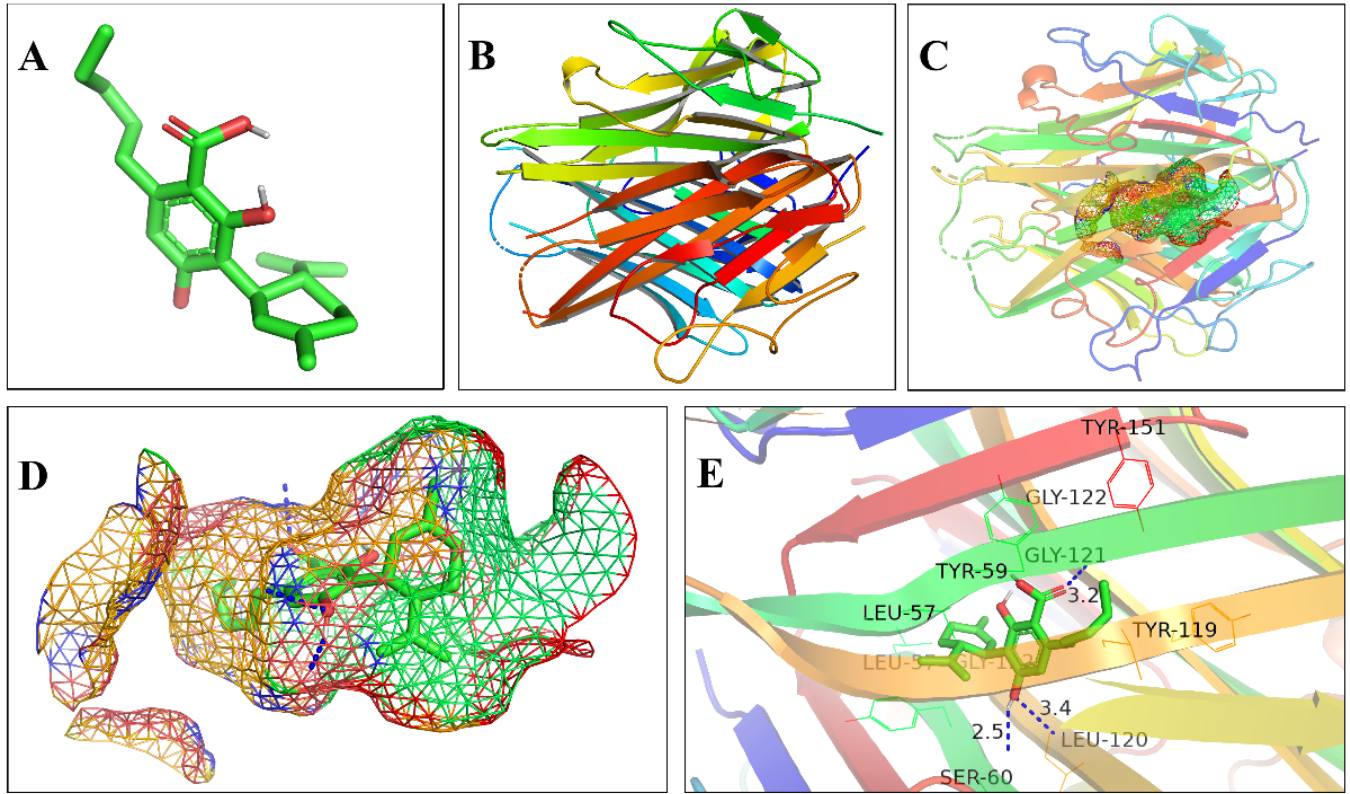

Figure 8. Molecular docking of CBDA to TNF. (A) 3D structure of CBDA ligand (carbon atoms and carbon-carbon bonds were green-colored, oxygen atoms were red-colored, and hydroxyl hydrogen atoms were gray-colored); (B) 3D structure of TNF protein targe; (C) The binding of CBDA to the active pocket of TNF shown in mesh surface; (D) the extracted and enlarged binding pocket; and (E) the binding sites between ligand and target (the protein target was shown as the rainbow-colored cartoon, the amino acid residues at the active sites were shown as colored ribbons with name and sequence numbers, and the hydrogen bonds were displayed by blue dashed lines with distance value in Angstrom).

\section{Conclusions}

We have identified the key cannabinoids from the Cannabis plant through text mining and screening of drug-like properties and retrieved the putative protein targets from the pharmacophore database for the building of the PPI network. Through the enrichment of GO and KEGG databases for biological functions, pathways, and diseases, various biological networks [i.e., target-pathway -disease, and target-(pathway)-target interaction] were constructed. Four functional modules with shared pathways and their association with various diseases were elucidated through the exploitation of network analysis. Eighteen essential protein targets and eight key cannabinoids were identified and verified by molecular docking simulation to be associated with the health benefits and medical harms of Cannabis use in humans. This study demonstrated that Cannabis exerted its pharmacological effects on humans through multi-components act via modulation of multiple essential protein targets to exhibit the desired disease efficacy, and the findings of this work await validation by preclinical and clinical studies.

Supplementary Materials: The following supporting information can be downloaded at: https:// www.mdpi.com/article/10.3390/app12042205/s1, Table S1-S6, Table S1. The drug-like properties of the 12 selected cannabinoids obtained by in silico prediction. Table S2. The putative targets of the twelve selected cannabinoids predicted using PharmMapper. Table S3. The results of GO function enrichment analysis. Table S4. The results of KEGG pathway enrichment analysis. Table S5. The categories of diseases related to the enriched KEGG pathways. Table S6. Integrated centrality values of protein targets in the functional modules.

Author Contributions: X.L. designed and conducted the work, performed data acquisition, analysis and interpretation, and drafted the manuscript; A.M.K. contributed to the literature search and participated in data/results discussion; F.J.N.V. reviewed and edited the manuscript; and Y.X. conceived the work, participated in data analysis and interpretation, and carried out critical revision for 
important intellectual content and final approval of the article. All authors have read and agreed to the published version of the manuscript.

Funding: This research was funded by the China Scholarship Council, grant number 201808535031.

Institutional Review Board Statement: Not applicable.

Informed Consent Statement: Not applicable.

Data Availability Statement: Not applicable.

Conflicts of Interest: The authors declare no conflict of interest.

\section{Abbreviations}

\begin{tabular}{|c|c|}
\hline$\Delta^{9}-\mathrm{THC}$ & $\Delta^{9}$-tetrahydrocannabinol \\
\hline$\Delta^{8}-\mathrm{THC}$ & $\Delta^{8}$-tetrahydrocannabinol \\
\hline $11-\mathrm{OH}-\Delta^{9}-\mathrm{THC}$ & 11-hydroxy- $\Delta^{9}$ - tetrahydrocannabinol \\
\hline$\Delta^{9}-\mathrm{THCA}$ & $\Delta^{9}$-tetrahydrocannabinolic acid \\
\hline$\Delta^{9}-\mathrm{THCV}$ & $\Delta^{9}$-tetrahydrocannabivarin \\
\hline THCVA & tetrahydrocannabivarinic acid \\
\hline $\mathrm{CBN}$ & cannabinol \\
\hline CBD & cannabidiol \\
\hline CBDA & cannabidiolic acid \\
\hline CBDV & cannabidivarin \\
\hline CBDVA & cannabidivarinic acid \\
\hline $\mathrm{CBC}$ & cannabichromene \\
\hline CBCA & cannabichromenic acid \\
\hline CBCVA & cannabichromevarinic acid \\
\hline CBG & cannabigerol \\
\hline CBGA & cannabigerolic Acid \\
\hline CBGVA & cannabigevarolic acid \\
\hline CAT & catalase \\
\hline COMT & catechol-O-methyltransferase \\
\hline CYP17A1 & cytochrome P450 family 17 subfamily A member 1 \\
\hline GSTA2 & glutathione S-transferase alpha 2 \\
\hline GSTM3 & glutathione S-transferase mu 3 \\
\hline GSTP1 & glutathione S-transferase pi 1 \\
\hline HMOX1 & heme oxygenase 1 \\
\hline AKT1 & AKT serine/threonine kinase 1 \\
\hline CASP9 & caspase 9 \\
\hline PLCG1 & phospholipase C gamma 1 \\
\hline PRKCA & protein kinase $C$ alpha \\
\hline PRKCB & protein kinase $C$ beta \\
\hline CYCS & cytochrome c, somatic \\
\hline TNF & tumor necrosis factor \\
\hline CNR1 & cannabinoid receptor 1 \\
\hline CNR2 & cannabinoid receptor 2 \\
\hline CREB1 & cAMP responsive element binding protein 1 \\
\hline GRIN2B & glutamate ionotropic receptor NMDA type subunit 2B \\
\hline $\mathrm{GO}$ & the Gene Ontology \\
\hline KEGG & the Kyoto Encyclopedia of Genes and Genomes \\
\hline ETCM & the Encyclopedia of Traditional Chinese Medicine \\
\hline TCMSP & Traditional Chinese Medicine Systems Pharmacology \\
\hline ADMET & Absorption, distribution, metabolism, excretion, and toxicity \\
\hline DL & drug-likeness \\
\hline BBB & blood-brain ratio \\
\hline
\end{tabular}




\section{References}

1. McPartland, J.M. Cannabis systematics at the levels of family, genus, and species. Cannabis Cannabinoid Res. 2018, 3, $203-212$. [CrossRef]

2. Pellati, F.; Borgonetti, V.; Brighenti, V.; Biagi, M.; Benvenuti, S.; Corsi, L. Cannabis sativa L. and nonpsychoactive cannabinoids: Their chemistry and role against oxidative stress, inflammation, and cancer. Biomed. Res. Int. 2018, 2018, 1691428. [CrossRef] [PubMed]

3. Small, E.; Beckstead, H. Cannabinoid phenotypes in Cannabis sativa. Nature 1973, 245, 147-148. [CrossRef] [PubMed]

4. Schluttenhofer, C.; Yuan, L. Challenges towards revitalizing hemp: A multifaceted crop. Trends Plant Sci. 2017, 22, 917-929. [CrossRef] [PubMed]

5. Greenway, F.L.; Kirwan, J.P. Medical marijuana-An obesity problem or opportunity. Int. J. Obes. 2019, 43, 761-762. [CrossRef] [PubMed]

6. Salentijn, E.M.; Zhang, Q.; Amaducci, S.; Yang, M.; Trindade, L.M. New developments in fiber hemp (Cannabis sativa L.) breeding. Ind. Crops Prod. 2015, 68, 32-41. [CrossRef]

7. Mozaffarian, D.; Griffin, T.; Mande, J. The 2018 Farm Bill-Implications and Opportunities for Public Health. JAMA 2019, 321, 835-836. [CrossRef]

8. Avila, C.; Massick, S.; Kaffenberger, B.H.; Kwatra, S.G.; Bechtel, M. Cannabinoids for the Treatment of Chronic Pruritus: A Review. Am. Acad. Dermatol. 2020, 82, 1205-1212. [CrossRef]

9. $\quad$ Deidda, R.; Avohou, H.T.; Baronti, R.; Davolio, P.L.; Pasquini, B.; Del, B.M.; Hubert, C.; Hubert, P.; Orlandini, S.; Furlanetto, S. Analytical quality by design: Development and control strategy for a LC method to evaluate the cannabinoids content in cannabis olive oil extracts. J. Pharm. Biomed. Anal. 2019, 166, 326-335. [CrossRef]

10. Freeman, T.P.; Hindocha, C.; Green, S.F.; Bloomfield, M.A. Medicinal use of cannabis based products and cannabinoids. BMJ 2019, 365, 11141. [CrossRef]

11. Brown, J.D.; Winterstein, A.G. Potential Adverse Drug Events and Drug-Drug Interactions with Medical and Consumer Cannabidiol (CBD) Use. J. Clin. Med. 2019, 8, 989. [CrossRef]

12. Bigand, T.; Anderson, C.L.; Roberts, M.L.; Shaw, M.R.; Wilson, M. Benefits and adverse effects of cannabis use among adults with persistent pain. Nurs. Outlook 2019, 67, 223-231. [CrossRef]

13. Richins, R.D.; Rodriguez-Uribe, L.; Lowe, K.; Ferral, R.; O'Connell, M.A. Accumulation of bioactive metabolites in cultivated medical Cannabis. PLoS ONE 2018, 13, e0201119. [CrossRef] [PubMed]

14. Liu, C.; Sadat, S.H.; Ebisumoto, K.; Sakai, A.; Panuganti, B.A.; Ren, S.; Goto, Y.; Haft, S.; Fukusumi, T.; Ando, M. Cannabinoids promote progression of HPV positive head and neck squamous cell carcinoma via p38 MAPK activation. Clin. Cancer Res. 2020, 26, 2693-2703. [CrossRef] [PubMed]

15. Gonçalves, J.; Rosado, T.; Soares, S.; Simão, A.Y.; Caramelo, D.; Luís, Â.; Fernández, N.; Barroso, M.; Gallardo, E.; Duarte, A.P. Cannabis and Its Secondary Metabolites: Their Use as Therapeutic Drugs, Toxicological Aspects, and Analytical Determination. Medicines 2019, 6, 31. [CrossRef] [PubMed]

16. Sumanasekera, W.; Spio, K. Cannabis (Marijuana): Psychoactive Properties, Addiction, Therapeutic Uses, and Toxicity. J. Addict. Behav. Ther. Rehabil. 2016, 5, 2.

17. Velez, L.I.; O'Connell, E.; Rice, J.; Benitez, F.; LoVecchio, F. Adverse reactions to cannabis and cannabinoids. Emerg. Med. Rep. 2018, 39, 1-30.

18. Steele, G.; Arneson, T.; Zylla, D. A comprehensive review of cannabis in patients with cancer: Availability in the USA, general efficacy, and safety. Curr. Oncol. Rep. 2019, 21, 10. [CrossRef]

19. Keehbauch, J.T.; Rensberry, M. Effectiveness, Adverse Effects, and Safety of Medical Marijuana. Am. Fam. Physician 2015, 92, 856-863.

20. Viudez-Martínez, A.; García-Gutiérrez, M.S.; Medrano-Relinque, J.; Navarrón, C.; Navarrete, F.; Manzanares, J. Cannabidiol does not display drug abuse potential in mice behavior. Acta. Pharmacol. Sin. 2019, 40, 358-364. [CrossRef]

21. Volkow, N.D.; Baler, R.D.; Compton, W.M.; Weiss, W.R. Adverse health effects of marijuana use. N. Engl. J. Med. 2014, 370, 2219-2227. [CrossRef] [PubMed]

22. Ho, C.; Martinusen, D.; Lo, C. A review of cannabis in chronic kidney disease symptom management. Can. J. Kidney Health Dis. 2019, 6, 1-14. [CrossRef]

23. Kolb, B.; Saber, H.; Fadel, H.; Rajah, G. The endocannabinoid system and stroke: A focused review. Brain Circ. 2019, 5, 1-7. [PubMed]

24. Malek, N.; Starowicz, K. Joint problems arising from lack of repair mechanisms: Can cannabinoids help? Br. J. Pharmacol. 2019, 176, 1412-1420. [CrossRef] [PubMed]

25. Feeney, K.E.; Kampman, K.M. Adverse effects of marijuana use. Linacre Q. 2016, 83, 174-178. [CrossRef]

26. Nourbakhsh, M.; Miller, A.; Gofton, J.; Adeagbo, B. Cannabinoid hyperemesis syndrome: Reports of fatal cases. J. Forensic. Sci. 2019, 64, 270-274. [CrossRef] [PubMed]

27. Dong, J.; Wang, N.-N.; Yao, Z.-J.; Zhang, L.; Cheng, Y.; Ouyang, D.; Lu, A.-P.; Cao, D.-S. ADMETlab: A platform for systematic ADMET evaluation based on a comprehensively collected ADMET database. J. Cheminform. 2018, 10, 29-40. [CrossRef] [PubMed] 
28. Wang, X.; Shen, Y.; Wang, S.; Li, S.; Zhang, W.; Liu, X.; Lai, L.; Pei, J.; Li, H. PharmMapper 2017 update: A web server for potential drug target identification with a comprehensive target pharmacophore database. Nucleic Acids Res. 2017, 45, W356-W360. [CrossRef] [PubMed]

29. Szklarczyk, D.; Gable, A.L.; Lyon, D.; Junge, A.; Wyder, S.; Huerta-Cepas, J.; Simonovic, M.; Doncheva, N.T.; Morris, J.H.; Bork, P. STRING v11: Protein-protein association networks with increased coverage, supporting functional discovery in genome-wide experimental datasets. Nucleic Acids Res. 2019, 47, D607-D613. [CrossRef]

30. Shannon, P.; Markiel, A.; Ozier, O.; Baliga, N.S.; Wang, J.T.; Ramage, D.; Amin, N.; Schwikowski, B.; Ideker, T. Cytoscape: A Software Environment for Integrated Models of Biomolecular Interaction Networks. Genome Res. 2003, 13, 2498-2504. [CrossRef]

31. Batagelj, V.; Mrvar, A. Pajek-Analysis and visualization of large networks. In Graph Drawing Software; Mutzel, P., Jucunger, M., Leipert, S., Eds.; Springer: Berlin/Heidelberg, Germany, 2004; pp. 77-103.

32. Thangaraj, M.; Amutha, S. Mgephi: Modified gephi for effective social network analysis. IJSRSET 2018, 3, 39-50.

33. Zuo, H.; Zhang, Q.; Su, S.; Chen, Q.; Yang, F.; Hu, Y. A network pharmacology-based approach to analyse potential targets of traditional herbal formulas: An example of Yu Ping Feng decoction. Sci. Rep. 2018, 8, 11418. [CrossRef] [PubMed]

34. Trott, O.; Olson, A.J. AutoDock Vina: Improving the speed and accuracy of docking with a new scoring function, efficient optimization, and multithreading. J. Comput. Chem. 2010, 31, 455-461. [CrossRef] [PubMed]

35. Mooers, B.H. Shortcuts for Faster Image Creation in PyMOL. Protein Sci. 2019, 29, 268-276. [CrossRef] [PubMed]

36. Morris, G.M.; Huey, R.; Lindstrom, W.; Chen, Q.; Yang, F.; Hu, Y. AutoDock4 and AutoDockTools4: Automated docking with selective receptor flexibility. J. Comput. Chem. 2009, 30, 2785-2791. [CrossRef] [PubMed]

37. O'Boyle, N.M.; Banck, M.; James, C.A.; Morley, C.; Vandermeersch, T.; Hutchison, G.R. Open Babel: An open chemical toolbox. J Cheminform. 2011, 3, 1-14. [CrossRef] [PubMed]

38. Saadi, H.; Nouali Taboudjemat, N.; Rahmoun, A.; Imbernón, B.; Pérez-Sánchez, H.; Cecilia, J.M. Efficient GPU-based parallelization of solvation calculation for the blind docking problem. J. Supercomput. 2020, 76, 1980-1998. [CrossRef]

39. Baron, E.P. Medicinal properties of cannabinoids, terpenes, and flavonoids in cannabis, and benefits in migraine, headache, and pain: An update on current evidence and cannabis science. Headache Curr. 2018, 58, 1139-1186. [CrossRef]

40. Protti, M.; Brighenti, V.; Battaglia, M.R.; Anceschi, L.; Pellati, F.; Mercolini, L. Cannabinoids from Cannabis sativa L.: A New Tool Based on HPLC-DAD-MS/MS for a Rational Use in Medicinal Chemistry. ACS Med. Chem. Lett. 2019, 10, 539-544. [CrossRef]

41. Urits, I.; Borchart, M.; Hasegawa, M.; Kochanski, J.; Orhurhu, V.; Viswanath, O. An Update of Current Cannabis-Based Pharmaceuticals in Pain Medicine. Pain Ther. 2019, 8, 41-51. [CrossRef]

42. Talarico, G.; Trebbastoni, A.; Bruno, G.; de Lena, C. Modulation of the Cannabinoid System: A New Perspective for the Treatment of the Alzheimer's Disease. Curr. Neuropharmacol. 2019, 17, 176-183. [CrossRef] [PubMed]

43. Carla, A.; Antonio, G.-N. Adverse effects of cannabinoids. Epileptic Disord. 2020, 22, $29-32$.

44. Panlilio, L.V.; Zanettini, C.; Barnes, C.; Solinas, M.; Goldberg, S.R. Prior exposure to THC increases the addictive effects of nicotine in rats. Neuropsychopharmacology 2013, 38, 1198-1208. [CrossRef]

45. Cadoni, C.; Pisanu, A.; Solinas, M.; Acquas, E.; Chiara, G. Behavioural sensitization after repeated exposure to $\Delta^{9}$-tetrahydrocannabinol and cross-sensitization with morphine. Psychopharmacology 2001, 158, 259-266. [CrossRef] [PubMed]

46. Jalili, M.; Salehzadeh-Yazdi, A.; Gupta, S.; Wolkenhauer, O.; Yaghmaie, M.; Resendis-Antonio, O.; Alimoghaddam, K. Evolution of centrality measurements for the detection of essential proteins in biological networks. Front. Physiol. 2016, 7, 375. [CrossRef]

47. Kendall, D.A.; Yudowski, G.A. Cannabinoid receptors in the central nervous system: Their signaling and roles in disease. Front. Cell Neurosci. 2017, 10, 294. [CrossRef]

48. Zou, S.; Kumar, U. Cannabinoid receptors and the endocannabinoid system: Signaling and function in the central nervous system. Int. J. Mol. Sci. 2018, 19, 833. [CrossRef]

49. Hopkins, A.L. Network pharmacology: The next paradigm in drug discovery. Nat. Chem. Biol. 2008, 4, 682-690. [CrossRef]

50. Kano, M.; Ohno-Shosaku, T.; Hashimotodani, Y.; Uchigashima, M.; Watanabe, M. Endocannabinoid-mediated control of synaptic transmission. Physiol. Rev. 2009, 89, 309-380. [CrossRef]

51. Guindon, J.; Hohmann, A.G. The endocannabinoid system and pain. CNS Neurol. Disord. Drug Targets 2009, 8, 403-421. [CrossRef]

52. Di Marzo, V.; Stella, N.; Zimmer, A. Endocannabinoid signalling and the deteriorating brain. Nat. Rev. Neurosci. 2015, 16, 30-42. [CrossRef] [PubMed]

53. Schacht, J.P.; Hutchison, K.E.; Filbey, F.M. Associations between cannabinoid receptor-1 (CNR1) variation and hippocampus and amygdala volumes in heavy cannabis users. Neuropsychopharmacology 2012, 37, 2368-2376. [CrossRef] [PubMed]

54. Hartman, C.A.; Hopfer, C.J.; Haberstick, B.; Rhee, S.; Crowley, T.J.; Corley, R.P.; Hewitt, J.K.; Ehringer, M.A. The association between cannabinoid receptor 1 gene (CNR1) and cannabis dependence symptoms in adolescents and young adults. Drug Alcohol Depend. 2009, 104, 11-16. [CrossRef] [PubMed]

55. Agrawal, A.; Lynskey, M.T. Candidate genes for cannabis use disorders: Findings, challenges and directions. Addiction 2009, 104, 518-532. [CrossRef]

56. Trivedi, M.K.; Panda, P.; Sethi, K.K.; Gangwar, M.; Mondal, S.C.; Jana, S. Solid and liquid state characterization of tetrahydrocurcumin using XRPD, FT-IR, DSC, TGA, LC-MS, GC-MS, and NMR and its biological activities. J. Pharm. Anal. 2020, 10, 334-345. [CrossRef]

57. Khaksar, S.; Bigdeli, M.R. Intra-cerebral cannabidiol infusion-induced neuroprotection is partly associated with the TNF$\alpha /$ TNFR1/NF-kB pathway in transient focal cerebral ischaemia. Brain Inj. 2017, 31, 1932-1943. [CrossRef] 
58. Silva, R.L.; Silveira, G.T.; Wanderlei, C.W.; Cecilio, N.T.; Maganin, A.G.; Franchin, M.; Marques, L.M.; Lopes, N.P.; Crippa, J.A.; Guimarães, F.S. DMH-CBD, a cannabidiol analog with reduced cytotoxicity, inhibits TNF production by targeting NF-kB activity dependent on A2A receptor. Toxicol. Appl. Pharmacol. 2019, 368, 63-71. [CrossRef]

59. Ligresti, A.; Moriello, A.S.; Starowicz, K.; Matias, I.; Pisanti, S.; De Petrocellis, L.; Laezza, C.; Portella, G.; Bifulco, M.; Di Marzo, V. Antitumor activity of plant cannabinoids with emphasis on the effect of cannabidiol on human breast carcinoma. J. Pharmacol. Exp. Ther. 2006, 318, 1375-1387. [CrossRef]

60. Liemburg, E.J.; Bruins, J.; van Beveren, N.; Islam, M.A.; Alizadeh, B.Z.; Bruggeman, R.; Wiersma, D.; Cahn, W.; Kahn, R.; de Haan, L. Cannabis and a lower BMI in psychosis: What is the role of AKT1. Schizophr. Res. 2016, 176, 95-99. [CrossRef]

61. Lee, L.-C.; Cho, Y.-C.; Lin, P.-J.; Yeh, T.-C.; Chang, C.-Y.; Yeh, T.-K. Influence of genetic variants of the N-methyl-D-aspartate receptor on emotion and social behavior in adolescents. Neural Plast. 2016, 2016, 6851592. [CrossRef]

62. Enoch, M.A.; Rosser, A.A.; Zhou, Z.; Mash, D.C.; Yuan, Q.; Goldman, D. Expression of glutamatergic genes in healthy humans across 16 brain regions; altered expression in the hippocampus after chronic exposure to alcohol or cocaine. Behav. Brain Funct. 2014, 13, 758-768. [CrossRef] [PubMed]

63. Barbado, M.V.; Medrano, M.; Caballero-Velázquez, T.; Álvarez-Laderas, I.; Sánchez-Abarca, L.; García-Guerrero, E.; MartínSánchez, J.; Rosado, I.V.; Piruat, J.I.; Gonzalez-Naranjo, P. Cannabinoid derivatives exert a potent anti-myeloma activity both in vitro and in vivo. Int. J. Cancer. 2017, 140, 674-685. [CrossRef]

64. Lanza Cariccio, V.; Scionti, D.; Raffa, A.; Iori, R.; Pollastro, F.; Diomede, F.; Bramanti, P.; Trubiani, O.; Mazzon, E. Treatment of periodontal ligament stem cells with MOR and CBD promotes cell survival and neuronal differentiation via the PI3K/Akt/mTOR pathway. Int. J. Mol. Sci. 2018, 19, 2341. [CrossRef] [PubMed]

65. Hettema, J.M.; An, S.S.; van den Oord, E.J.; Neale, M.C.; Kendler, K.S.; Chen, X. Association study of CREB1 with Major Depressive Disorder and related phenotypes. Am. J. Med. Genet. B Neuropsychiatr. Genet. 2009, 150, 1128-1132. [CrossRef] [PubMed]

66. Burcescu, I.; Wigg, K.; King, N.; Vetro, A.; Kiss, E.; Katay, L.; Kennedy, J.; Kovacs, M.; Barr, C. Association study of CREB1 and childhood-onset mood disorders. Am. J. Med. Genet. B Neuropsychiatr. Genet. 2005, 137, 45-50. [CrossRef]

67. Levran, O.; Peles, E.; Randesi, M.; Correa da Rosa, J.; Ott, J.; Rotrosen, J.; Adelson, M.; Kreek, M.J. Synaptic plasticity and signal transduction gene polymorphisms and vulnerability to drug addictions in populations of European or African ancestry. CNS Neurosci. Ther. 2015, 21, 898-904. [CrossRef]

68. Han, S.; Yang, B.-Z.; Kranzler, H.R.; Liu, X.; Zhao, H.; Farrer, L.A.; Boerwinkle, E.; Potash, J.B.; Gelernter, J. Integrating GWASs and human protein interaction networks identifies a gene subnetwork underlying alcohol dependence. Am. J. Hum. Genet. 2013, 93, 1027-1034. [CrossRef]

69. Sun, J.; Huang, L.-C.; Xu, H.; Zhao, Z. Network-assisted prediction of potential drugs for addiction. Biomed. Res. Int. 2014, 2014, 258784. [CrossRef] [PubMed]

70. Li, X.; Xu, X.; Wang, J.; Yu, H.; Wang, X.; Yang, H.; Xu, H.; Tang, S.; Li, Y.; Yang, L. A system-level investigation into the mechanisms of Chinese Traditional Medicine: Compound Danshen Formula for cardiovascular disease treatment. PLoS ONE 2012, 7, e43918. [CrossRef] [PubMed]

71. Xiang, Z.; Sun, H.; Cai, X.; Chen, D.; Zheng, X. The study on the material basis and the mechanism for anti-renal interstitial fibrosis efficacy of rhubarb through integration of metabonomics and network pharmacology. Mol. Biosyst. 2015, 11, 1067-1078. [CrossRef]

72. Zhang, J.; Zhao, J.; Ma, Y.; Wang, W.; Huang, S.; Guo, C.; Wang, K.; Zhang, X.; Zhang, W.; Wen, A. Investigation of the multi-target mechanism of guanxin-shutong capsule in cerebrovascular diseases: A systems pharmacology and experimental assessment. Front. Pharmacol. 2021, 12, 1177. [CrossRef] [PubMed] 